\title{
Processo de readequação de um planejamento familiar: construção de autonomia feminina em uma Unidade Básica de Saúde no Ceará
}

\author{
Process of restructuring of a family planning: construction of female \\ autonomy at a Healthcare center in Ceará \\ Proceso de readecuación de una planificación familiar: la construcción de \\ la autonomía femenina en un Centro de atención primaria en Ceará
}

\author{
Rayanne Branco dos Santos | rayannebranco@gmail.com \\ Universidade Estadual Vale do Acaraú, Sobral, CE, Brasil. \\ Raíssa Mont'Alverne Barreto | raissinha@ @hotmail.com \\ Universidade Estadual Vale do Acaraú, Sobral, CE, Brasil. \\ Ana Caroline Lira Bezerra | ana.caroline bezerra@hotmail.com \\ Universidade Estadual Vale do Acaraú, Sobral, CE, Brasil. \\ Maristela Inês Osawa Vasconcelos | miosawa@gmail.com \\ Universidade Estadual Vale do Acaraú, Sobral, CE, Brasil.
}

\section{Resumo}

O estudo em que se baseia este artigo objetivou relatar a experiência na qual se processou a readequação do modelo de assistência ao planejamento familiar de uma Unidade Básica de Saúde (UBS) de um município do Ceará. Após discussão com a equipe de saúde da Unidade, foram entregues convites a mulheres em idade reprodutiva para que estas se fizessem presentes no novo modelo de planejamento familiar da Unidade. Assim, iniciou-se uma abordagem grupal acerca do planejamento familiar, com introdução de orientações acerca dos métodos contraceptivos e de doenças sexualmente transmissíveis (DSTs). Após isso, havia um atendimento individual para o repasse de informações sigilosas e a prescrição do método de acordo com o consenso entre a paciente e a enfermeira. Verificou-se, assim, estreitamento no vínculo enfermeiro-paciente, além dos benefícios para a própria Unidade, visto que os atendimentos passaram a ser mais eficazes. Concluiu-se que os processos de educação em saúde são dinâmicos e que readequações são válidas, considerando-se as necessidades dos pacientes.

Palavras-chaves: planejamento familiar; educação sexual; saúde reprodutiva; Estratégia Saúde da Família; doenças sexualmente transmissiveis. 


\begin{abstract}
This article bases on a study that aimed to report the experience of restructuring the family planning care at an Unidade Básica de Saúde - UBS (Healthcare center) of a municipality in Ceará. After discussions with the health team of the UBS, invitations were delivered to women at reproductive age to take part in the new model of family planning at the UBS. Thus they began a group approach about family planning, introducing guidelines about contraception and sexually transmitted diseases (STDs). Afterwards, there was an individual service to deal with private information and prescription of the method according to the consensus between the patient and the nurse. Thus the nurse-patient bond was narrowed and brought benefits for the UBS itself, insofar as the services have become more effective. It was concluded that health education processes are dynamic and restructurings are valid, considering the needs of patients.
\end{abstract}

Keywords: family planning; sexual education; reproductive health; Family Health Strategy; sexually transmitted diseases.

\title{
Resumen
}

El presente artículo es basado en estudio que ha tenido como objetivo relatar la experiencia en la que se ha efectuado la readecuación del modelo de atención a la planificación familiar de una Unidade Básica de Saúde - UBS (Centro de atención primaria) en un municipio de Ceará. Después de la discusión con la equipo de la UBS, invitaciones fueron entregadas a mujeres en edad reproductiva para que participasen en el nuevo modelo de planificación familiar de la UBS. Así comenzó un enfoque de grupo sobre la planificación familiar, con la introducción de directrices sobre la anticoncepción y enfermedades de transmisión sexual (ETSs). Después de eso, había un servicio individual para referirse a la información confidencial y para la prescripción del procedimiento de acuerdo con el consenso entre el paciente y la enfermera. Ha sido estrechado así el vínculo enfermera-paciente, y ha tenido beneficios para la propia UBS, ya que los servicios se han tornado más eficaces. Se concluye que los procesos de educación para la salud son dinámicos y que readecuaciones son válidas, teniendo en cuenta las necesidades de los pacientes.

Palabras clave: planificación familiar; educación sexual; salud reproductiva; Estrategia de Salud Familiar; enfermedades de transmisión sexual.

Contribuição dos autores:

Concepção e desenho do estudo: Rayanne Branco dos Santos Lima, Raíssa Mont'Alverne Barreto, Ana Caroline Lira Bezerra

Aquisição, análise ou interpretação dos dados: Rayanne Branco dos Santos Lima, Raíssa Mont'Alverne Barreto, Ana Caroline Lira Bezerra

Redação do manuscrito: Rayanne Branco dos Santos Lima, Raíssa Mont'Alverne Barreto, Ana Caroline Lira Bezerra

Revisão crítica do conteúdo intelectual: Maristela Inês Osawa Vasconcelos

Declaração de conflito de interesses: não apresenta conflitos de interesse

Fontes de financiamentos: não houve

Considerações éticas: Resolução 466/12

Agradecimento/Contribuições adicionais: À Unidade Básica de Saúde (UBS), onde foi realizado o estudo, nossa gratidão!

Histórico do artigo: Submetido: 20.jan.2016 | Aceito: 31.maio.2016 | Publicado: 30.set.2016.

Apresentação anterior: nenhuma

Licença CC BY-NC atribuição não comercial. Com essa licença é permitido acessar, baixar (download), copiar, imprimir, compartilhar, reutilizar e distribuir os artigos, desde que para uso não comercial e com a citação da fonte, conferindo os devidos créditos de autoria e menção à Reciis. Nesses casos, nenhuma permissão é necessária por parte dos autores ou dos editores. 


\section{Introdução}

A O conceito de educação sexual e reprodutiva foi implantado no Brasil em consequência do aumento considerável de infecções sexualmente transmissíveis (ISTs), Aids, gravidez na adolescência e da sexualidade precoce desde a década de 1980. No início da década de 1990, o Ministério da Educação (MEC) e o Ministério da Saúde (MS) passaram a estimular projetos de educação sexual, com vistas ao controle da natalidade, disseminação de meios contraceptivos e propostas avançadas de planejamento familiar (PF)1.

De acordo com a Constituição Federal e a Lei n 9.263, de 12 de janeiro de 1996, o PF, definido como responsabilidade do Estado, deve proporcionar condições para que homens e mulheres tenham acesso a informações, meios, métodos e técnicas para a regulação da sua fecundidade. Tal conquista se mantém na atual Política Nacional de Atenção Integral à Saúde da Mulher (PNAISM) como ação para reduzir a mortalidade materna e perinatal por causas evitáveis, além de fomentar a implementação de ações que contribuam para a garantia dos direitos humanos das mulheres ${ }^{2}$.

Essa proposta de PF, oferecida principalmente pela Estratégia de Saúde da Família (ESF), deve abranger um processo de informação e de educação aos casais e à população em geral sobre a reprodução, a importância da família na comunidade, o papel da mulher, do pai e do filho dentro desse contexto e, finalmente, sobre as repercussões de tudo isso na comunidade 3 . Dessa forma, a informação adequada em planejamento familiar é imprescindível, uma vez que possibilita ao cliente autonomia para escolher o melhor método contraceptivo de acordo com a necessidade e o bem-estar do casal. Além disso, os serviços de saúde devem dispor de métodos e técnicas para o controle da fecundidade.

O início da vida sexual na adolescência difere entre os países. No mundo, os adolescentes têm a primeira relação sexual, em média, aos 17,3 anos e as mulheres tornam-se sexualmente ativas mais cedo. No Brasil, 30,5\% dos adolescentes já tiveram relação sexual alguma vez. Contudo, o início da vida sexual dos meninos foi mais precoce, aos16,2 anos, e o das meninas se deu aos 17,94. Essas informações evidenciam a necessidade desses adolescentes estarem informados acerca dos riscos aos quais se expõem e de como planejar o futuro no que se refere ao planejamento familiar.

No entanto, em alguns municípios brasileiros verificam-se dificuldades para a efetiva implementação do planejamento familiar, sendo as mais importantes: a oferta limitada de métodos contraceptivos, falta de consciência multiprofissional e influência do poder médico, seguidas pelo espaço físico inadequado, falta de capacitação profissional, dificuldade da mulher assimilar e seguir orientações. Essas dificuldades devem ser reconhecidas e transpostas para o efetivo uso desses serviços. Assim, delinear o panorama dessa assistência pode contribuir para o planejamento e a programação das atividades, de modo a revisar prioridades, subsidiando a tomada de decisões e contribuindo para o alcance de melhores resultados em termos de impacto sobre a saúde sexual e reprodutiva da população ${ }^{5}$.

Nessa perspectiva, em face da vivência no Internato 1 do curso de Enfermagem de uma Universidade Estadual no Ceará, cuja inserção foi na Estratégia de Saúde da Família de um bairro de periferia, verificaramse fragilidades e limitações na operacionalização do planejamento familiar, as quais se restringiam à prescrição, renovação de receitas e entrega dos métodos anticoncepcionais disponibilizados na Unidade Básica de Saúde (UBS). Além disso, verificou-se um alto índice de gestantes adolescentes adscritas na unidade (20), fazendo-se necessário, portanto, orientações de qualidade acerca dos métodos contraceptivos para obtenção de resultados positivos, uma vez que a eficiência do processo educativo aumenta as possibilidades de efetividade do planejamento familiar. A qualidade da informação transmitida permite que o usuário compreenda e retenha a informação, sendo sujeito pleno de direitos, socialmente responsável e com capacidade de posicionamento frente à sua saúde sexual e reprodutiva.

Nesse contexto, o estudo em pauta objetivou relatar a experiência vivida, na qual se processou a implantação de um novo modelo de assistência ao planejamento familiar de uma UBS em um bairro 
localizado no Ceará, visando ao desenvolvimento de relações comunitárias e sociais mais saudáveis, com espaços para compartilhamento de vivências e experiências entre as mulheres, aquisição de novos conhecimentos, fortalecimento do vínculo profissional-usuária e autonomia para melhor escolha dos métodos anticoncepcionais.

\section{Método}

A priori buscou-se uma aproximação do campo de estudo, onde foi identificada a necessidade de aperfeiçoamento do modelo de planejamento familiar ofertado na unidade, uma vez que tal assistência era direcionada apenas às mulheres em idade reprodutiva e tinha como principal finalidade a entrega dos métodos anticoncepcionais disponíveis e a renovação de receitas pelas enfermeiras em serviço. Cada profissional atendia em um dia específico e, dessa forma, o atendimento realizava-se de forma breve e individualizada, com longa fila de espera e transmissão de informações sucintas e superficiais dos profissionais para as usuárias.

No entanto, as informações oferecidas em planejamento familiar não devem apenas enfatizar os métodos anticoncepcionais considerados eficazes; é também fundamental abordar e oferecer a variedade dos métodos, bem como elucidar os aspectos imprescindíveis relativos à saúde sexual e reprodutiva ${ }^{5}$.

Dessa maneira, as iniciativas para reestruturação do novo modelo de planejamento familiar efetuaramse a partir de reuniões semanais com os profissionais de saúde para pontuar as fragilidades e limitações decorrentes da atual assistência prestada às usuárias. Assim, mediante relatos e percepções dos profissionais de saúde da UBS, buscou-se, conjuntamente, construir uma nova abordagem de trabalho, voltada aos interesses dessas mulheres como cidadãs e agentes do seu próprio processo de educação e de libertação, considerando o núcleo familiar e não somente a mulher, uma vez que essa forma de planejamento é um método de prevenção e de intervenção na saúde da família. Atentou-se também para a implementação de orientações dentro do planejamento familiar relacionadas ao risco de infecções sexualmente transmissíveis e para comunicar a livre oferta de preservativos que a unidade disponibiliza sem necessidade de prescrição.

O planejamento do novo modelo também se deu junto às agentes comunitárias de saúde (ACS), que se tornam indispensáveis nesse processo, uma vez que residem na comunidade e a ela pertencem. Além disso, conhecemos anseios e necessidades das mulheres de suas respectivas áreas, configurando-se como elo entre a Unidade de Saúde e as mulheres da comunidade. Deste modo, com vistas a organizar o planejamento e verificar a quantidade de mulheres que fazem uso dos métodos contraceptivos disponibilizados no planejamento familiar, optou-se por organizá-lo por área de cada agente de saúde, tendo cada uma delas um dia específico para o atendimento de acordo com a enfermeira da área. O quadro a seguir (Quadro 1) mostra o esquema elaborado com o objetivo de atender as necessidades de cada área. As enfermeiras foram representadas por algarismos arábicos $(1,2,3 \ldots)$ e as agentes de saúde, por letras do alfabeto (A, B,C,D...). 
Quadro 1 - Organização esquemática dos dias de planejamento familiar da UBS estudada

\begin{tabular}{|c|c|c|c|c|}
\hline \multicolumn{5}{|c|}{ Enfermeira 1} \\
\hline Dias da semana & $1^{0}$ segunda-feira & $2^{\circ}$ segunda-feira & 30 segunda-feira & 40 segunda-feira \\
\hline Agente de Saúde & $A$ & B & $\mathrm{C}$ & $\mathrm{D}$ \\
\hline \multicolumn{5}{|c|}{ Enfermeira 2} \\
\hline Dias da semana & $1^{0}$ terça-feira & $2^{\circ}$ terça-feira & $3^{0}$ terça-feira & 40 terça-feira \\
\hline Agente de Saúde & $E$ & $\mathrm{~F}$ & G & $\mathrm{H}$ \\
\hline \multicolumn{5}{|c|}{ Enfermeira 3} \\
\hline Dias da semana & 10 quarta-feira & $2^{\circ}$ quarta-feira & 30 quarta-feira & $4^{\circ}$ quarta-feira \\
\hline Agente de Saúde & I & J & $\mathrm{K}$ & $\mathrm{L}$ \\
\hline \multicolumn{5}{|c|}{ Enfermeira 4} \\
\hline Dias da semana & 10 quinta-feira & $2^{\circ}$ quinta-feira & $3^{\circ}$ quinta-feira & $4^{\circ}$ quinta-feira \\
\hline Agente de Saúde & $M$ & $\mathrm{~N}$ & 0 & $P$ \\
\hline
\end{tabular}

Fonte: Elaborado pelos autores (2016).

Nessa perspectiva, as ACS entregaram convites para as mulheres em idade reprodutiva, contendo informações condizentes com o novo modelo de participação do planejamento familiar realizado pelos profissionais de saúde em um dia e turno específico da semana para cada profissional. Nele foi estabelecido um horário para reunir todas as mulheres, de forma coletiva, e outro em uma sala privativa, com o objetivo de transmitir informações necessárias a cada mulher presente sobre seu método, renovar receita, tirar dúvidas, trocar o atual método ou iniciar algum tipo de método contraceptivo de acordo com as necessidades das usuárias além de fornecer aconselhamento sexual. Além disso, reservou-se um espaço para acolhimento individual de mulheres que desejavam uma conversa particular por não acharem conveniente fazê-la no coletivo.

Tal estratégia foi importante por valorizar a individualidade dentro do coletivo, além da valorização da troca de experiências, do diálogo, do respeito à cultura, valores e compartilhamento de vivências, sendo importante destacar o ganho na confiança e fortalecimento do vínculo profissional-usuária.

Para fins de registro, além da ficha do e-SUS utilizada pela Unidade, abriu-se um livro de ata dividido por área, tendo por líder a enfermeira. Nele registra-se o nome da cliente do planejamento familiar, o método contraceptivo utilizado por ela e o nome de sua agente de saúde. Esse registro tem a finalidade de estimar quantas mulheres estão participando do planejamento familiar, além de identificar os métodos contraceptivos mais utilizados e verificar quais áreas precisam de intervenção de busca ativa.

Diante disso, a nova abordagem de trabalho visa despertar as usuárias para o planejamento da família em sua integralidade e busca mobilizá-las para comprometerem seus parceiros na construção conjunta de um planejamento diário de sua família, não só relativo ao número de filhos, mas também a como criá-los, passando-lhes valores, afeto, hábitos de cidadania e ética, para uma vivência familiar mais saudável, feliz e, por conseguinte, uma sociedade melhor ${ }^{5}$.

\section{Resultados e Discussão}

A estratégia de saúde da família do lócus do estudo em pauta abrange um número expressivo de mulheres em idade fértil. O bairro possui intensa marginalidade e boa parte dos seus habitantes vive do tráfico. Os determinantes sociais são muito fortes e verificou-se que a maioria das mulheres e adolescentes que ali residem acredita que o papel da mulher é cuidar do lar e saciar o parceiro sexualmente. Em virtude disso, as internas da ESF foram sensibilizadas a tentar contribuir com a ampliação dos conhecimentos dessas mulheres, 
não apenas no que se refere à saúde sexual e reprodutiva, mas também nas demais áreas fragilizadas. Cabe salientar que a ESF do bairro fica aberta para o atendimento de segunda a sexta, das 7 às 17 horas.

Verificou-se que, anteriormente, as mulheres do bairro estavam habituadas apenas a renovar receitas e a usufruir do método utilizado sem recepção de orientações. A princípio, demonstraram resistência ao novo modelo, pois antes era algo rápido. Foi, portanto, necessário desmistificar essa postura e construir um espaço para o diálogo, a troca referente aos problemas familiares e aos fatores que interferem na decisão de planejar a família. Assim, a adesão e fidelidade ao novo modelo de planejamento familiar foram sendo conquistadas gradualmente.

Nesse ínterim, a fase do ciclo de vida da família deve ser avaliada, bem como as suas crenças, valores e tradições, e o planejamento deve ser conduzido na forma de programa, passo a passo, com tarefas que tornem o processo ativo para os usuários. Além disso, o planejamento familiar deve estar fundamentado na perspectiva do desenvolvimento, permitindo que a família faça sua própria avaliação, elabore seu plano e gerencie de forma sustentável o crescimento dos membros³.

A UBS estudada dispõe de álbuns seriados contendo imagens e textos referentes aos diferentes métodos anticoncepcionais, tanto os hormonais quanto os de barreiras, bem como ilustrações de ISTs e sua prevenção. Esses álbuns passaram a ser aliados no momento do planejamento, tornando a conversa mais dinâmica e ilustrativa.

Atualmente, a reunião do PF na ESF do bairro estudado se inicia com as boas-vindas e a explicação do novo modelo de PF pela enfermeira da área. Na sequência, realiza-se uma orientação utilizando os álbuns seriados e outros recursos visuais e auditivos para ilustrar e enfatizar as informações repassadas. Esse momento instiga dúvidas, anseios e medos que as mulheres possuem, tornando-o interativo e fértil para o aprendizado.

Assim, as discussões ao longo dos encontros fizeram com que as mulheres se interessassem à medida que se tornavam cientes das mudanças ocorridas no corpo pelo uso do anticoncepcional e das doenças que são evitáveis pelo uso do preservativo de barreira. Isso possibilitou constatar que o conhecimento, atitude, autonomia e confiança das mulheres participantes frente aos métodos contraceptivos eram limitados e insuficientes, uma vez que tais usuárias, muitas vezes, não conseguiam identificar seu próprio método e compreender a sua utilidade.

Um estudo elaborado, tendo por motivação a quantidade expressiva de mulheres grávidas na Bahia apresentou importantes reflexões que corroboram as constatações do presente estudo. Os autores refletem sobre o que deve ser planejado e respondem a essa indagação ao sinalizarem que os atuais planejamentos familiares estão restritos aos métodos contraceptivos para escolher o quantitativo de filhos, quando na verdade essa ferramenta de saúde pública deveria abranger a educação desses filhos, a renda familiar, os aspectos afetivos do lar, entre outras causas sociais ${ }^{3}$. Evidencia-se que o PF tem suas raízes muito inseridas no biológico e no físico, mas que pouco é falado das questões sociais, que são fundamentais no processo e fazem toda a diferença na saúde familiar.

Nesse contexto, com o novo modelo de planejamento familiar centrado na transmissão de informações e orientações referentes à saúde sexual e reprodutiva e avaliação do ciclo de vida familiar, houve a facilitação do diálogo, compartilhamento de vivências, contemplação da troca de conhecimento e expressão de ideias.

A partir daí, houve possibilidade de reformulação de conceitos e de valores, pois se acreditava - e acreditase ainda - que a educação crítica e consciente é a base para a mudança de valores e consequentemente de um novo pensar e agir, sendo, portanto, o fator educacional considerado uma variável mediadora da efetividade do planejamento familiar ${ }^{6}$.

Nessa perspectiva, a remodelação do planejamento familiar da Unidade de Saúde estudada contribuiu para a promoção da saúde de famílias ao modificar os determinantes de saúde em benefício da qualidade de vida, provocando mudanças sociais e econômicas a partir do novo modelo de assistência ao planejamento familiar baseado na sustentabilidade e no ciclo de vida da família. 
Evidenciou-se também que o atendimento tem sido mais proveitoso e otimizado, uma vez que, anteriormente, após a triagem realizada pelos profissionais, todo o restante do turno era dedicado a receber mulheres para o planejamento sem hora marcada, fornecendo-lhes fichas a fim de organizar a ordem do atendimento. No entanto, às vezes, ficavam um longo período sem atendimento algum. Então, com o novo modelo, as mulheres estão se adaptando a chegar no horário marcado, a participar de um momento de orientação, bem como a reavaliar o seu método contraceptivo e a ter um momento a sós com a enfermeira para discutir suas dúvidas e ter sua receita renovada.

Com a finalidade de abranger as mulheres que trabalham fora do lar, buscou-se criar uma declaração de comparecimento ao PF para fins comprobatórios, em situações em que comparecem na unidade em horário comercial. Essa estratégia tem sido favorável para o grupo, visto que a periodicidade dos encontros para elas geralmente é mensal ou até trimestral, de acordo com o método utilizado. Anteriormente, o acesso dessas mulheres era muito limitado, em geral intermediado por uma parente ou até mesmo pela agente de saúde. Entretanto, hoje em dia, elas têm participado ativamente na escolha dos seus métodos contraceptivos.

Assim, o novo método utilizado permitiu também a criação de um vínculo maior entre enfermeiras, internas de enfermagem e as pacientes, visto que o momento é exclusivo para conversar com mais calma, ficar mais à vontade e aprender com as dúvidas que surgem, diferentemente da forma anterior, em que o atendimento era individual e a demanda era elevada, configurando-se em um atendimento restrito, a informações breves e superficiais que refletiam diretamente em consequências importantes para o desenvolvimento familiar.

Durante os encontros coletivos, à medida que a profissional fornecia informações sobre educação sexual, trocas de olhares repletos de dúvidas sempre surgiam, principalmente quando se tratava das adolescentes. O anseio de saber mais e de entender como evitar uma possível gravidez era extraído do semblante de algumas que, às vezes, por timidez ou vergonha, não questionavam de início, mas aos poucos conseguiam captar e compreender o sentido das informações transmitidas ao serem sanadas questões semelhantes às suas, Gradualmente adquiriam liberdade e autonomia dentro do grupo com capacidade de posicionamento frente à sua saúde sexual e reprodutiva.

Sob essa nova perspectiva, o sentimento de autonomia esteve perceptível ao se extrair de algumas mulheres que o planejamento familiar as ajudava a ter os seus filhos no momento que elas escolhessem e se sentissem plenamente preparadas. Percebeu-se ainda, que essa "autonomia" esteve muito relacionada às condições sociais e econômicas, uma vez que elas consideravam importante postergar a gestação devido à pouca condição financeira de criar um filho naquele momento.

Assim, esse sentimento também esteve presente em outro estudo, no qual o PF foi considerado uma ponte para uma vida melhor, permitindo às mulheres evitar gestações indesejadas e terem filhos conforme suas condições econômicas. Evitar filhos também foi uma decisão como suporte para uma vida menos sofrida e, ao mesmo tempo, livre de certas dificuldades vivenciadas na família e na sociedade ${ }^{2}$.

Outro fator importante do novo modelo de PF foram as informações obtidas por meio dos registros no livro de ata, as quais permitiram evidenciar que as áreas em que as mulheres participavam de forma frequente das reuniões de PF eram equivalentes àquelas com menores índices de gravidez na adolescência e como menor número de gestantes em geral. O oposto também foi constatado, revelando que a não assiduidade de mulheres pertencentes a determinada área apresentava maior número de gestantes, entre elas adolescentes.

Essa constatação é corroborada por estudos que mencionam que a ausência de programas de planejamento familiar adequados à demanda dos adolescentes nos serviços públicos de saúde também tem sido discutida como fator importante na etiologia da gestação adolescente. Desse modo, o investimento em estratégias de conhecimento de meios de planejamento e organização familiar é fundamental no processo de informação da população. O investimento em materiais educativos e na mídia favorece a propagação da ideia e contribui para uma população mais consciente7. 
Pelos registros, conseguiu-se também mensurar quais os tipos de métodos contraceptivos mais utilizados pelas mulheres do bairro estudado, revelando a injeção mensal (noretisterona 50mg + estradiol 5mg) como o método mais utilizado. Ao serem questionadas sobre o motivo da escolha, as mulheres mencionaram que o esquecimento as impede de utilizar o ciclo 21 (levenogestrel 0,15mg + estradiol 0,03mg) com eficácia, aumentando assim as chances de gravidez indesejada em virtude da falha do prosseguimento hormonal. Porém, mesmo diante desse impasse, o ciclo 21 ainda é o segundo mais utilizado pelas mulheres do bairro.

Os métodos de barreiras são mistificados por algumas mulheres, principalmente os femininos (diafragma e camisinha feminina). Elas afirmam que, esteticamente, a camisinha feminina não lhes agrada e que o diafragma é desagradável. Quanto às camisinhas masculinas, as mulheres mencionam que seus parceiros não gostam de utilizar e, assim, somente elas se responsabilizam pela ação de evitar a gestação. Referente a isso, salienta-se a necessidade de orientar o uso de preservativo de barreira não apenas para evitar concepção, mas também para evitar ISTs.

Dessa forma, fica evidenciada a desigualdade quanto à responsabilidade do homem e da mulher no controle da fecundidade, constatando o pouco interesse e engajamento masculino no planejamento familiar. Incluir e trazer o parceiro para participação efetiva no programa ainda constitui um desafio para os profissionais de saúde.

A Política Nacional de Atenção Integral à Saúde do Homem (PNAISH) enfatiza questões de gênero e, ao abordar a população masculina em relação ao cuidado com a própria saúde e a saúde de sua família, afirma que são necessárias mudanças de paradigma. Destaca-se que, além dos aspectos educacionais, entre outras ações/atividades, os serviços públicos de saúde precisam estar organizados de modo a acolher e fazer com que o homem sinta-se parte integrante deles. No que tange ao planejamento familiar e aos direitos reprodutivos e sexuais, é necessário superar a restrição às mulheres da responsabilidade das práticas contraceptivas, assegurando aos homens o direito de participação na regulação da fecundidade e na reprodução ${ }^{8}$.

Diante dessas questões e durante a realização do novo modelo de planejamento familiar da Unidade de Saúde em estudo, identificou-se a necessidade de participação do parceiro nas orientações sexuais em virtude de relatos de mulheres quanto às dificuldades para introduzir novos métodos, como a camisinha. Assim, pensou-se em estratégias que pudessem trazer os parceiros para participar das orientações sexuais no coletivo ou no momento de acolhimento individual, caso fosse a preferência, e poder escolher, juntamente com a mulher, o método mais eficaz e adequado ao casal.

Porém a participação masculina ainda é insuficiente frente a importância do homem nas discussões sexuais como sujeito ativo para planejamento da sua família. Sabe-se que o ideal é ter um planejamento familiar que envolva o homem e a mulher como sujeitos corresponsáveis e conscientes no processo de planejar a família, e não somente a mulher, visto que é um problema que afeta a todos e vai além de questões que envolvam identidade de gênero e/ou orientação sexual. Portanto, é fundamental a construção de parcerias igualitárias, baseadas no respeito entre os parceiros e em responsabilidades compartilhadas 9

Nesse contexto, sugere-se a capacitação e incentivo para mudança de paradigmas de profissionais que lidem diretamente com o planejamento familiar para sensibilizar a população masculina a participar de forma mais direta no planejamento das famílias, de modo a minimizar as dificuldades relacionadas às questões de gênero e envidar esforços na construção de um programa efetivo ${ }^{10}$.

Assim, para as internas de enfermagem, o novo modelo assistencial ao planejamento familiar tem sido gratificante, pois além de proporcionar melhorias para a população feminina local, também trouxe benefícios para a Unidade de Saúde. Isso proporcionou sentimento de alegria e satisfação por poder contribuir com o serviço, de maneira a agradecer os conhecimentos e experiência adquirida no período do internato. 


\section{Considerações Finais}

Identificar fragilidades no serviço contribui para a formação profissional à medida que instiga o senso crítico e político do acadêmico de modo a buscar melhorias para a população e para aperfeiçoar a assistência prestada. Na experiência relatada foi possível perceber a mobilização realizada por internas de enfermagem ao reformularem junto à equipe da Unidade Básica de Saúde o modelo de planejamento familiar.

Verificou-se progresso para a Unidade, posto que o atendimento tornou-se mais rápido e eficaz, e as mulheres que participam do planejamento familiar passaram a ser coparticipantes no processo de escolha do método contraceptivo. Além disso, começaram a compreender os fatores de risco para uma relação desprotegida e o que acontece em seu corpo com o uso dos hormônios.

Assim, essa nova forma de abordagem permitiu superar o modelo de rotina, e tornou-o mais dinâmico, participativo e expressivo. Percebeu-se que esse processo de (re) construção fugiu do simples fato de entregar medicamentos contraceptivos e ampliou sua abordagem, com vistas ao autocuidado, à autoestima, à autonomia, à maior oportunidade de decisões e escolhas, além do espaço de difusão das dúvidas, angústias, desejos e anseios.

Diante disso, à medida que participam das orientações, essas mulheres tornam-se cientes dos riscos das infecções sexualmente transmissíveis, bem como da forma correta de preveni-las. Dessa forma, tornam-se também disseminadoras dos conhecimentos adquiridos, repassando para as amigas, vizinhas e parentes e, desse modo, auxiliam na propagação da promoção da saúde e da autonomia de escolher o momento certo de se iniciar uma família.

Vale salientar que a equipe de enfermagem aderiu com facilidade às novas sugestões para a execução do planejamento familiar e, com isso, o estudo trouxe reflexões para tais profissionais, que, atarefadas com seus afazeres diários, muitas vezes não conseguiam identificar uma forma de aprimorar seus atendimentos, sendo preciso um olhar externo para modificar as práticas de saúde.

A resistência das mulheres a se adaptarem aos novos horários de planejamento familiar constituiu uma limitação do estudo; porém, a adesão e fidelidade ao novo modelo de assistência às mulheres foram sendo conquistadas gradualmente, concretizando-se como rotina na ESF do bairro estudado. Contudo, ainda é preciso investir mais em outros assuntos que abranjam temáticas sociais como educação dos filhos, renda familiar e relacionamento interpessoal, que são fatores importantes para o desenvolvimento de um lar agradável e, consequentemente, de uma sociedade mais estável.

\section{Referências}

1. Henriques R, Brandt MEA, Junqueira RD, Chamusca A, organizadores. Gênero e diversidade sexual na escola: reconhecer diferenças e superar preconceitos [Internet]. Brasília, DF. 2007[citado em 2015 ago 15]. (Cadernos SECAD, 4). p. 1-87. Disponível em: http://portal.mec.gov.br/secad/arquivos/pdf/escola protege/caderno5.pdf.

2. Silva MR, Araújo KNC, Bastos LAC, Moura ERF. Planejamento familiar: significado para mulheres em idade reprodutiva. Cienc Saude Colet [Internet]. 2011 maio [citado em 2015 ago 15]; 16(5):2415-24. Disponível em: http://www.scielo.br/scielo.php?script=sci arttext\&pid=S1413-81232011000500010.

3. Santos JC, Freitas PM. Planejamento familiar na perspectiva do desenvolvimento. Cienc Saude Colet [Internet]. 2011 mar [citado em 2015 ago 15];16(3):1813-20. Disponível em: http://www.scielo.br/ scielo.php?script=sci arttext\&pid=S1413-81232011000300017.

4. Vanzin R, Aerts D, Alves G, Câmara S, Palazzo L, Elicker E et al. Vida sexual de adolescentes escolares da rede pública de Porto Velho-RO. Aletheia[Internet]. 2013 ago [citado em 2015 ago 15];(41)109-20. Disponível em: http://www.redalyc.org/pdf/1150/115031073009.pdf.

5. Pierre LAS, Clapis MJ. Planejamento familiar em Unidade de Saúde da Família. Rev Latino-Am Enfermagem [Internet] 2010 nov-dez [citado em 2015 ago 15];18(6):[8 telas]. Disponível em: http:// www.scielo.br/pdf/rlae/v18n6/pt 17.pdf. 
6. Pariz J, Mengarda CF; Frizzo GB. A atenção e o cuidado à gravidez na adolescência nos âmbitos familiar, político e na sociedade: uma revisão da literatura. Saúde Soc [Internet] 2012 [citado em 2015 ago 15];21(3):623-36. Disponível em: http://www.scielo.br/pdf/sausoc/v21n3/09.pdf.

7. Pereira QLC, Silva CBDCA, Pelzer MT, Lunardi VL, Siqueira HCH. Processo de (re)construção de um grupo de planejamento familiar: uma proposta de educação popular em saúde. Texto Contexto Enferm [Internet] 2007 abr-jun [citado em 2015 ago 15];16(2):320-5. Disponível em: http://www.scielo.br/pdf/ tce/v16n2/a16v16n2.pdf.

8. Casarin ST, Siqueira HCH. Planejamento familiar e a saúde do homem na visão das enfermeiras. Esc Anna Nery[Internet]. 2014 out-dez [citado em 2015 ago 15];18(4):662-68.Disponível em: http://www. scielo.br/scielo.php?script=sci arttext\&pid=S1414-81452014000400662.

9. Morais $A C B$, Ferreira AG, Almeida KL, Quirino GS. Participação masculina no planejamento familiar e seus fatores intervenientes. Rev Enferm UFSM[Internet]. 2014 jul-set [citado em 2015 ago 15];4(3):498-508.Disponível em: http://periodicos.ufsm.br/reufsm/article/view/9998/pdf.

10. Brasil. Ministério da Saúde. Secretaria de Atenção à Saúde. Departamento de Atenção Básica. Saúde sexual e saúde reprodutiva [Internet]. Brasília, DF, 2010 [citado em 2015 ago 15]. (Normas e Manuais Técnicos, série A; Cadernos de Atenção Básica, n. 26). 300 p. Disponível em: http://189.28.128.100/ dab/docs/publicacoes/cadernos ab/abcad26.pdf. 